\title{
A estreita relação entre o estudo da língua e as concepções teóricas de Bakhtin[i]
}

\author{
Fabrícia Cavichioli \\ Mestranda em Letras - UFSM \\ E-mail: fabriciacavichioli@yahoo.com.br
}

Para Bakhtin, o agir humano não se dá independente da interação; nem o dizer fora do agir (Faraco, 2003:112).

Resumo:O propósito deste estudo é fazer um levantamento teórico sobre algumas concepções bakhtiniana que estão interligadas diretamente com o uso da língua. Para tanto, estão presentes neste recorte teórico, a saber: a própria noção de língua, noções de interação verbal e dialogismo, noções de enunciado e gêneros do discurso, e também a concepção de gênero na perspectiva dialógica da linguagem na perspectiva bakhtiniana. Considerando este estudo, estamos cientes de que as contribuições de Bakhtin para os estudos lingüísticos são extremamente importantes, pois a construção de suas teorias, apesar de anos de existência, ainda servem de alicerce para a reformulação e construção de novos conceitos para os estudos inovadores da linguagem.

Palavras-chave: Concepções teóricas - língua - perspectiva bakhtiniana

\section{Considerações iniciais}

Bakhtin não era considerado pelos estudiosos da língua, um lingüista. Isso ocorria pelo fato de que seus estudos eram realizados e direcionados, especialmente, para a área da literatura e da Teoria da Comunicação, não contemplando, portanto, devidamente o estudo da língua. Partindo dessa constatação, não podemos ignorar que Bakhtin forma um conjunto de idéias, que aborda temas alicerçados para o estudo das realidades humanas, tais como, a linguagem, o sujeito, as relações entre sujeito e sociedade, etc.

Tais idéias nos fazem acreditar que Bakhtin também se interessou pelo estudo da língua, mas em um viés diferenciado de alguns lingüistas (Saussure, Schleicher, por exemplo). Suas concepções e conceituações teóricas sobre determinados termos (enunciado, dialogismo, interação verbal, etc) são embasadas no uso da língua (atividade humana), ou seja, ela serve de instrumento para a construção e a possível concretização de seus saberes teóricos.

De acordo com Bakhtin (1992), as atividades humanas, por mais variadas que sejam, estão sempre relacionadas com o uso da língua. A língua concretiza nossos enunciados, sejam eles orais ou escritos, concretos e únicos, que emanam dos integrantes de uma ou outra esfera da atividade humana. O enunciado reflete as condições específicas e as finalidades de cada uma dessas esferas, não só pelo conteúdo temático e estilo verbal, mas também, e principalmente pela construção composicional.

Refletindo em relação a essas concepções teóricas interligadas com o uso da língua, decidi fazer neste artigo um levantamento teórico, recortando alguns pontos, os 
quais acredito que estejam estreitamente amarrados com o estudo da língua, ressalto, então: a própria noção de língua, noções de interação verbal e dialogismo, noções de enunciado e gêneros do discurso, e também a concepção de gênero na perspectiva dialógica da linguagem na perspectiva bakhtiniana.

\section{Preceitos teóricos}

\subsection{Língua e interação verbal}

Para Bakhtin (1995), a verdadeira substância da língua não é constituída por um sistema abstrato de formas lingüísticas nem pela enunciação monológica isolada, nem pelo ato psicofisiológico de sua produção, mas pelo fenômeno social da interação verbal, realizada através da enunciação ou das enunciações. Em outras palavras, a interação verbal constitui assim a realidade fundamental da língua.

A enunciação é o produto da interação de dois indivíduos socialmente organizados e, mesmo que não haja um interlocutor real, este pode ser substituído pelo representante médio do grupo social ao qual pertence o locutor. E, o diálogo, por sua vez, constitui uma das formas mais importante da interação verbal, mas podemos compreender a palavra "diálogo" num sentido mais amplo, isto é, não apenas como a comunicação em voz alta, de pessoas colocadas face a face, mas toda comunicação verbal, independente de seu tipo.

$\mathrm{Na}$ interação por meio do diálogo, Barros (1996), seguindo os preceitos de Bakhtin, enfatiza que o emissor e o receptor não podem ser considerados como caixas ou casas vazias de emissão e recepção de mensagens. Precisam ser reconhecidos como sujeitos "plenos" ou "preenchidos", tanto por qualidades modais necessárias a suas competências comunicativas, quanto por valores decorrentes das relações com o "extralingüístico" e com a sociedade. Isso nos faz pensar na concepção de sociabilidade de Bakhtin, onde o locutor e considerado um ser social. Concebidos como seres sociais, os locutores, são construídos ao mesmo tempo pela interação entre eles e pelas relações com o "extralingüístico" e a sociedade.

Rodrigues (2005:155), também salienta que no processo de interação verbal, "as palavras nos vêm de outros enunciados e remetem a eles; portanto, nessa perspectiva, como elementos do enunciado, elas não são "neutras", mas trazem consigo sentidos" (visões de mundo).

Dessa forma, a língua vive e evolui historicamente na comunicação verbal concreta, não no sistema abstrato das formas da língua nem no psiquismo individual dos falantes. Bakhtin (1995:124) conclui que a ordem metodológica para o estudo da língua deve ocorrer da seguinte maneira:

1ㅇ) "As formas e os tipos de interação verbal em ligação com as condições concretas em que se realiza".

20) "As formas das distintas enunciações, dos atos de fala isolados, em ligação estreita com a interação de que constituem os elementos, isto é, as categorias de atos de fala 
na vida e na criação ideológica que se prestam a uma determinação pela interação verbal".

3ㅇ) "A partir daí, exame das formas da língua na sua interpretação lingüística habitual”.

Para tanto, é nesta ordem que a língua se desenvolve e evolui. Primeiramente, as relações sociais evoluem, e num segundo momento, a comunicação e a interação verbal evoluem no quadro das relações sociais. As formas dos atos de fala evoluem em conseqüência da interação verbal, e o processo de evolução reflete, enfim, na mudança das formas da língua.

\subsection{Dialogismo}

Partindo das considerações de Barros (1996) em relação à área de interesse de Bakhtin, a autora afirma que, sem dúvida, o dialogismo, o do princípio dialógico era o tema dominante em seus estudos.

A concepção de linguagem de Bakhtin é dialógica, se a ciência humana tem método e objetos dialógicos, também suas idéias sobre o homem e a vida são marcada pelo princípio dialógico. Para Bakhtin (1992,35-36), “a alteridade define o ser humano, pois o outro é indispensável para sua concepção: é impossível pensar no homem fora das relações que o ligam ao outro". Em outras palavras, o autor explica que ser significa comunicar-se, pois a vida é dialógica por natureza.

Bakhtin considera o dialogismo o princípio constitutivo da linguagem e a condição do sentido do discurso. O autor insiste no fato de que o discurso não é individual: 1우) não é individual porque é construído entre pelo menos dois interlocutores que, por sua vez, são seres sociais; 2ํ) não é individual porque se constrói como um “dialogo entre discursos", ou seja, porque mantém relações com outros discursos.

Barros (1996) ainda destaca que, Bakhtin aponta no enunciado-discurso dois aspectos: o que vem da língua e o que vem do contexto. Concebe o enunciado como produto de uma enunciação ou de um contexto histórico, social, cultural, etc. É nesse contexto, que participantes interagem verbalmente com seus enunciados de forma concreta e ativa. O discurso que resulta desse processo é dialógico, pois requer reação-resposta ativa daquele a quem é destinado os enunciados.

Sendo assim, os enunciados, pelo seu papel e lugar, representam unidades concretas e únicas da comunicação discursiva, por outro, pela sua natureza dialógica (o dialogismo é constitutivo), não podem deixar de se tocar nessa cadeia, estando vinculados uns aos outros por relações dialógicas, que são relações de sentido (Rodrigues, 2005).

\subsection{Enunciado e gêneros do discurso}

É indispensável destacar, primeiramente, a heterogeneidade dos gêneros do discurso sejam eles orais ou escritos (relato familiar, carta, receita, textos literários dentre outros). Diante dessa diversidade pensamos na possibilidade de que não haja 
um terreno comum para seu estudo. Como colocar no mesmo terreno de estudo fenômenos tão díspares como as práticas cotidianas e os textos literários?

A diferenciação funcional parece tornar os traços comuns a todos os gêneros do discurso abstratos e inoperantes. Talvez isso explique o problema geral dos gêneros do discurso de nunca terem sido tratados de tal maneira.

Os gêneros literários foram os mais estudados, sendo enfatizado o ângulo artístico-literário e não os tipos de enunciados que se diferenciavam de outros tipos de enunciados, tendo, principalmente, a natureza verbal (lingüística) em comum (Bakhtin, 1992:280).

Os gêneros retóricos, por sua vez, também foram objeto de estudo. Esse estudo centrava mais sua atenção à natureza verbal do enunciado, ou seja, aos seus princípios constitutivos tais como: a relação com o ouvinte e a influência deste sobre o enunciado, a conclusão verbal peculiar ao enunciado.

$E$, por fim estudaram-se os gêneros do discurso cotidiano, sendo enfocados do ponto de vista da lingüística geral[ii]. Nessa fase de estudos, "não era possível conduzir à definição correta da natureza lingüística do enunciado, na medida em que se limitava pôr em evidencia a especificidade do discurso cotidiano oral, operando no mais das vezes com enunciados deliberadamente primitivos" (Bakhtin, 1992:281).

Rodrigues (2005), citando Bakhtin, salienta que a limitação dos estudos dos gêneros pode ter se originado, devido à diversidade e à heterogeneidade dos gêneros, resultantes da diversidade ideológica das diferentes esferas sociais, que poderiam fazer crer que essas características diversas e heterogêneas dos gêneros converteriam os seus traços comuns em algo abstrato e vazio de significado.

Mesmo que em outros textos do Círculo[iii], os gêneros também sejam nomeados e definidos como forma de discurso social, Bakhtin opta pelo termo gêneros do discurso, definindo-os como tipos relativamente estáveis de enunciados ou formas relativamente estáveis e normativas do enunciado. De acordo com Rodrigues (2005:163):

Essa é a natureza verbal comum dos gêneros a que o autor se refere, isto é, a relação dialética que estabelece entre os gêneros e os enunciados, ou seja, olha os gêneros a partir da sua historicidade e lhes atribui a mesma natureza dos enunciados, ao tomá-los como seus tipos históricos.

Para tanto, essa definição de gêneros que corre o risco de provocar uma visão reducionista quando não levada em consideração as idéias do Círculo, se deve ao significado mais corrente que os termos enunciado[iv] e tipo[v] têm na área da lingüística.

Devido a grande heterogeneidade dos gêneros do discurso, Bakhtin (1992) preocupa-se em conceituar gêneros primários e gêneros secundários. O autor não formaliza taxionomias dos gêneros, a não ser a distinção que estabelece entre dois grupos de gêneros, que denominou de gêneros primários (simples) e secundários 
(complexos), cuja diferenciação, está assentada na diferença funcional dos gêneros.

Os gêneros secundários do discurso - o romance, o teatro, o discurso científico, o discurso ideológico, etc. - aparecem em circunstâncias de uma comunicação cultural, mais complexa e relativamente mais evoluída, principalmente escrita: artística, científica, sociopolítica. (...) esses gêneros secundários absorvem e transmutam os gêneros primários (...). Os gêneros primários (conversa de salão, carta, relato cotidiano, etc), transformam-se dentro destes e adquirem uma característica particular: perdem sua relação imediata com a realidade existente e com a realidade dos enunciados alheios (Bakhtin, 1992: 281).

Bakhtin ressalta que muitos gêneros secundários, no seu processo de formação, absorvem e reelaboram alguns gêneros primários. Muitos gêneros nascem do hibridismo de outros gêneros, primários ou não. O gênero primário inserido (intercalados) no secundário, como uma carta dentro de um romance, perde sua ligação direta com a realidade, deixa de ser acontecimento da vida cotidiana. Partindo dessa afirmação, a carta no romance conserva sua forma e relevância cotidiana só como parte do romance, participando da realidade, apenas por meio do romance, como acontecimento artístico e não como acontecimento cotidiano.

O processo de intercalação é um dos lugares onde observar a plasticidade dos gêneros. Essa diferenciação tem grande importância teórica, pois é a razão pela qual a natureza do enunciado deve ser elucidada e definida por uma análise de ambos os gêneros.

O estudo da natureza dos enunciados e da diversidade dos gêneros de enunciados nas diferentes esferas da atividade humana é de extrema relevância para as áreas da lingüística e da filologia. Pois é um trabalho de pesquisa acerca de um material lingüístico concreto, ou seja, trabalha, inevitavelmente com enunciados concretos (escritos e orais), que se relacionam com as diferentes esferas da atividade e da comunicação.

De acordo com Bakhtin (1992: 282):

Ignorar a natureza do enunciado e as particularidades de gênero que assinalam a variedade do discurso em qualquer área do estudo lingüístico leva ao formalismo e à abstração, desvirtua a historicidade do estudo, enfraquece o vínculo existente entre a língua e a vida. A língua penetra na vida através dos enunciados concretos que a realizam, e é também através dos enunciados concretos que a vida penetra na língua. $O$ enunciado situa-se no cruzamento excepcionalmente importante de uma problemática.

Apoiado na idéia de que a língua funciona por meio dos enunciados concretos, Bakhtin aborda algumas áreas e alguns problemas da lingüística, começando pela estilística. O estilo está ligado aos gêneros do discurso. Os gêneros possuem um estilo individual, no entanto, nem todos são aptos a esse estilo.

Os gêneros literários são os mais propícios, neles o estilo individual "faz parte 
do empreendimento enunciativo enquanto tal e constitui uma das suas linhas diretrizes" (Bakhtin, 1992:283). Já os gêneros do discurso apresentam condições desfavoráveis para refletir a individualidade na língua, pois requerem uma forma padronizada, como por exemplo, a formulação do documento oficial, da ordem militar, da nota de serviço e outros.

A diversidade dos gêneros do discurso pode desvendar a variedade dos estratos e dos aspectos da personalidade individual, e o estilo individual pode relacionar-se de diferentes maneiras com a língua comum.

Quando tratamos do problema de estilo lingüístico ou funcional, podemos atestar o vínculo inseparável entre estilo e gênero. O estilo lingüístico ou funcional nada mais é senão "o estilo de um gênero peculiar a uma dada esfera da atividade e da comunicação humana" (Bakhtin, 1992: 283). As esferas conhecem os gêneros, que são apropriados à sua especificidade, aos quais correspondem determinados estilos. Por exemplo, uma dada função (seja ela cientifica, técnica, cotidiana ou outras) e dadas condições, específicas para cada uma das esferas da comunicação verbal, geram um dado gênero, ou seja, um determinado tipo de enunciado, relativamente estável do ponto de vista temático, composicional e estilístico.

Sendo assim, a separação entre estilo e gênero é resultado de uma série de problemas históricos. As mudanças históricas dos estilos da língua são indissociáveis das mudanças que se efetuam nos gêneros do discurso.

A língua escrita corresponde ao conjunto dinâmico e complexo constituído pelos estilos da língua, cujo peso respectivo e a correlação, dentro do sistema da língua escrita, se encontram num estado de contínua mudança (Bakhtin, 1895 - 1975: 285).

A língua escrita em seu desenvolvimento é marcada pelos gêneros do discurso (secundários: literários, científicos...; e primários: tipos do dialogo oral: linguagem cotidiana, familiar...). A ampliação da língua escrita que incorpora diversas camadas da língua popular acarreta em todos os gêneros a ampliação de um novo procedimento na organização e na conclusão do todo verbal e uma modificação do lugar que será reservado ao ouvinte, o que leva a uma maior ou menor reestruturação e renovação dos gêneros do discurso.

O estudo da natureza do enunciado e dos gêneros do discurso é extremamente importante para que possamos superar as noções simplificadas acerca da vida verbal (fluxo verbal), a comunicação. Essas noções ainda são válidas na ciência da linguagem.

\subsection{Gênero na concepção dialógica da linguagem}

Faraco (1996:122), embasado nos conceitos de Bakhtin, argumenta que "o caráter dialógico é o fator unificador de todas as atividades linguageiras, havendo também uma rica dialogia entre os gêneros do discurso". Considerando essa concepção, é importante lembrar a riqueza e a variedade dos gêneros do discurso que 
são infinitas, "pois a variedade da atividade humana é inesgotável e cada esfera dessa atividade comporta um repertório de gêneros do discurso que vai diferenciando-se e ampliando-se à medida que a própria esfera se desenvolve e fica mais complexa" (Bakhtin, 1992:279).

Bakhtin nos alerta para o fato de que apesar dos gêneros serem formas ágeis, em constante re-elaboração, fáceis de combinar, "para o individuo falante eles não deixam de ter um valor normativo: os gêneros são dados, não é ele que os cria" (Bakhtin, 1992:304):

Se não existissem os gêneros do discurso e se não os dominássemos, se tivéssemos de criá-los pela primeira vez no processo de fala, se tivéssemos que construir cada um de nossos enunciados, a comunicação verbal seria quase impossível (Bakhtin, 1992:302).

Bentes (2005:119) reflete a respeito da citação de Bakhtin, afirmando que é este o caráter normativo dos gêneros percebidos pelos falantes que lhes confere a "relativa estabilidade" mencionada pelo autor, estabilidade esta que é um princípio definidor dos gêneros. Sendo assim, pode-se atestar, seguramente, que os gêneros discursivos organizam nossa fala para que a comunicação possa acontecer entre os indivíduos.

Considerando uma das principais características que Bakhtin atribui aos gêneros: a heterogeneidade, não podemos conceituá-los (os gêneros) como produtos acabados à disposição dos falantes. Mesmo que Bakhtin considere os aspectos sóciohistóricos e dialógicos que definem a produção, a circulação e a recepção dos gêneros, ele não descarta a possibilidade de encararmos os gêneros do discurso como um "todo discursivo" que apresenta uma estrutura relativamente estável:

Para falar, utilizamos-nos sempre dos gêneros do discurso, ou seja, todos o s enunciados dispõem de uma forma padronizada e relativamente estável de estruturação de um todo. Um vasto repertório caracteriza os gêneros do discurso (orais e escritos). Na prática podemos usá-los com segurança e destreza, mas por um lado não podemos ignorar totalmente sua existência teórica. (...) Aprender a falar é aprender a estruturar enunciados, e os gêneros do discurso, por sua vez, organizam nossa fala, assim como organizam as formas gramaticais (sintáticas). (Bakhtin, 1992:301-302).

Conforme Bentes (2005), a estabilidade dos gêneros do discurso é valorizada por Bakhtin, justamente porque ele considera o seu caráter histórico e a sua importância para a efetiva comunicação entre as pessoas. Sendo assim, o autor não nega a flexibilidade, a maleabilidade, a plasticidade funcional e formal dos gêneros, mas afirma que o uso criativo exige o domínio dessa estruturação mais ou menos estável.

\section{Considerações finais}


Com a conclusão deste estudo teórico, no qual foram ressaltadas noções de interação verbal, língua, dialogismo, enunciado e gêneros do discurso, constatou-se que os aspectos abordados estão profundamente interligados com o estudo da língua. A língua é o instrumento chave para a conceituação das noções referidas. $O$ uso da língua se concretiza na forma de enunciados (orais e escritos) pelos participantes de uma ou outra esfera da atividade social. Então, como dizer que Bakhtin, não se interessou pelo estudo da língua?

No recorte teórico deste trabalho, fica evidente que o autor desenvolveu estudos relacionados à língua. O problema disso tudo, se estende para outra dimensão, ou melhor, deve-se a forma de como ele estudava a língua. Para Bakhtin, a verdadeira substância da língua é constituída pelo fenômeno social da interação verbal realizada por meio da enunciação ou das enunciações. Para ele a língua não pode estar isolada, fechada, ou seja, desvinculada ao contexto lingüístico real. É por tratar a língua neste viés que Bakhtin critica a radical postura saussuriana, que privilegia o caráter formal e estrutural do fenômeno lingüístico, em conseqüência disso, Bakhtin tenta trazer para o centro da cena dos estudos lingüísticos a noção de comunicação social.

Dessa forma, estamos cientes de que as contribuições de Bakhtin para os estudos lingüísticos são extremamente importantes, pois a construção de suas teorias, apesar de anos de existência, ainda servem de alicerce para a reformulação e construção de novos conceitos para os estudos inovadores da linguagem.

\section{Referências bibliográficas:}

BAKHTIN. M. M (1895-1975). Os gêneros do discurso. In: BAKHTIN. M. Estética da criação verbal. (Tradução: Maria Ermantina Galvão Gomes Pereira). São Paulo: Martins Fontes, 1992.

BAKHTIN. M (1973-1977). Língua, fala e enunciação. In: BAKHTIN. M. Marxismo e filosofia da linguagem. (tradução: Michel Lahud e Yara Frateschi Vieira) São Paulo: Hucitec, 1995.

. (1973-1977). A interação verbal. In: BAKHTIN. M. Marxismo e filosofia da linguagem. (tradução: Michel Lahud e Yara Frateschi Vieira) São Paulo: Hucitec, 1995.

BARROS. G. L. P de. (1996). Contribuições de Bakhtin às teorias do texto e do discurso. In: FARACO. C. A; TEZZA. C; CASTRO. G de. (Orgs). Diálogos com Bakhtin. Paraná: UFPR, 1996.

FARACO. A. C. (1996). O dialogismo como chave de uma antropologia filosófica. In: FARACO. C. A; TEZZA. C; CASTRO. G de. (Orgs). Diálogos com Bakhtin. Paraná: UFPR, 1996.

FARACO, C. A. Linguagem e diálogo. As idéias lingüísticas do Circulo de Bakhtin. Curitiba: Edições Criar, 2003.

BENTES, A. C. (2005). Gêneros e ensino: algumas reflexões sobre a produção de materiais didáticos para a educação de jovens e adultos. In: KARWOSKI. A. M; GAYDECZKA. B; BRITO. K. S. (Orgs). Gêneros textuais: reflexão e ensino. Palmas e União da Vitória, PR: Kaygangue, 2005.

RODRIGUES. R. H. (2005). Os gêneros do discurso na perspectiva dialógica da linguagem: a abordagem de Bakhtin. In: J. L. Meurer; A. Bonini; D. Motta- Roth (Orgs). Gêneros: teorias, métodos, debates. São Paulo, Parábola Editorial. 
[i] Trabalho desenvolvido no Programa de Pós-Graduação em Letras na disciplina de Lingüística Geral, sob a Orientação da Prof ${ }^{\mathrm{a}}$ Doutora Vera Pires, como requisito de avaliação parcial para o $1^{\text {o }}$ semestre de 2006.

[iil A escola de Saussure e seus continuadores mais recentes -os estruturalistas, os behavioristas americanos, os discípulos de Vossler que, aliás, tinham uma base totalmente diferente.

[iiil Círculo é a denominação atribuída pelos pesquisadores ao grupo de intelectuais russos que se reunia regularmente no período de 1919 a 1974, dentre os quais participavam Bakhtin, Voloshinov e Medvedev.

[iv] "Para Adam (1992), um gênero seria formado por vários tipos de texto (seqüências/enunciados). Entretanto, a noção de enunciado do Círculo (por exemplo, um romance é um enunciado) não avaliza essa leitura" (Rodrigues, 2005:163).

[v] A palavra tipo, nos estudos lingüísticos do texto, acabou sendo associada à teoria de Adam sobre as seqüências textuais, denominadas tipos textuais. 